\title{
PRODUCT DEVELOPMENT SIMULATION WITH MULTICRITERIA ANALYSIS
}

\author{
Kostanjevec, T. ${ }^{*}$ Polajnar, A. ${ }^{*} \&$ Kostanjevec, M.* \\ *University of Maribor, Faculty of Mechanical Engineering, Smetanova 17, 2000 Maribor, Slovenia \\ ${ }^{* *}$ First Grammar School Maribor, Trg generala Maistra 1, 2000 Maribor, Slovenia \\ E-Mail: tomaz.kostanjevec@uni-mb.si
}

\begin{abstract}
Effective product development rests on a product's design ability to create a positive product experience. This involves complex transformation of product information from customers to engineers to production to sales and back to customers. This work presents the concept of simulating the development of a new product. The multicriteria analysis of product development in a multi-dimensional space is being used. Based on simulation, the model shows in which direction the product will be developed on the basis of existing information. In the set multi-dimensional space, in which each observation parameter has a designated polar dimensional in terms of dependence on time, development on the basis of selected products is simulated. In an innovative way and in the case of sanitary fittings, simulation of the development of a new product in the early stages of design ideas is shown.

(Received in April 2008, accepted in October 2008. This paper was with the authors 3 months for 1 revision.)
\end{abstract}

Key Words: Product Development, Simulation, Multicriteria Analysis, Multidimensional Space

\section{INTRODUCTION}

The development of a new product involves creating a new design concept and building and testing prototypes. One way of interpreting what engineers do during this process is to think about how they decide whether a design is attractive. Through they follow a variety of technical specifications and established test standards, if we cut through all the formal detail, at the core of the evaluation, engineers are simulating what future customers will experience [1].

Simulation of the new product development is conducted in accordance with the company's strategy and market needs. We maintain that the companies do not use simulation as a way for potential new product often enough. This article presents how a company simulates the development of a new product in the form of a projected trend. Predicting trends can be very inconvenient, since it requires a large number of collected and processed data, by both the market and the company. Very few companies do the "homework" and keep quality data, which are an important source of developing new products. Simulation of development in the creation of ideas at the very beginning - fuzzy front end - is extremely unpleasant, if the market is not unified and does not have a strategy or collected data [2]. While there are a number of forecasting techniques available, it is important to realize that not all of them are appropriate for every forecasting situation [3]. The technique for progress is simulation, which significantly reduces the possibility of errors, which a product can "cause" on the market. A toolbox approaches therefore recommended for applying new product forecasting technique. The concept used was substantially presented in the article [3], where it presents the likely path of a future product on the basis of an automated model. The authors state forecasting and modelling of new products take different forms, from the matrices [3] to speculative sales and simulation test markets [4]. 
In developing the product with the use of multi-parameter analysis, through graphic display, a company can determine with mathematical - statistical certainty that the direction trend has a much higher chance of success on the market than if these methods were not used. Specifically, simulation tools are becoming very useful for saving time in the design-buildtest phase of product development [5].

Product development also includes research within the market with regard to customer needs [2], [4] product forecasting [6] and test marketing. A number of applications, marked by different views, led to a deeper understanding of how to join and use the information regarding customers and product engineering in simulating, designing, testing, starting and managing new products. To further disclose the contents, methods and applications of the above, more integrative views and articles on the topic of product development were published [7], [8].

New challenges and opportunities are reflected in global markets, global competitiveness, the global spread of engineering knowledge and with communication technologies. The use of multicriteria analysis with product development represents a new challenge and an opportunity in design research and new product forecasting [9], [10].

The classical model of product development is presented as a concept of consumption simulation in Fig. 1, where in the process of product development and later production runs in the return path of the production function and the users. The price of errors and simulations at the stage of the production function is lower than the errors in the simulated market and lower than the errors in the direct entry to the market [11]. Companies simulate the development of the product and its use, but the time pressure of competition and low-quality collection of information is directly related to the costs and often with unclear answers [1].

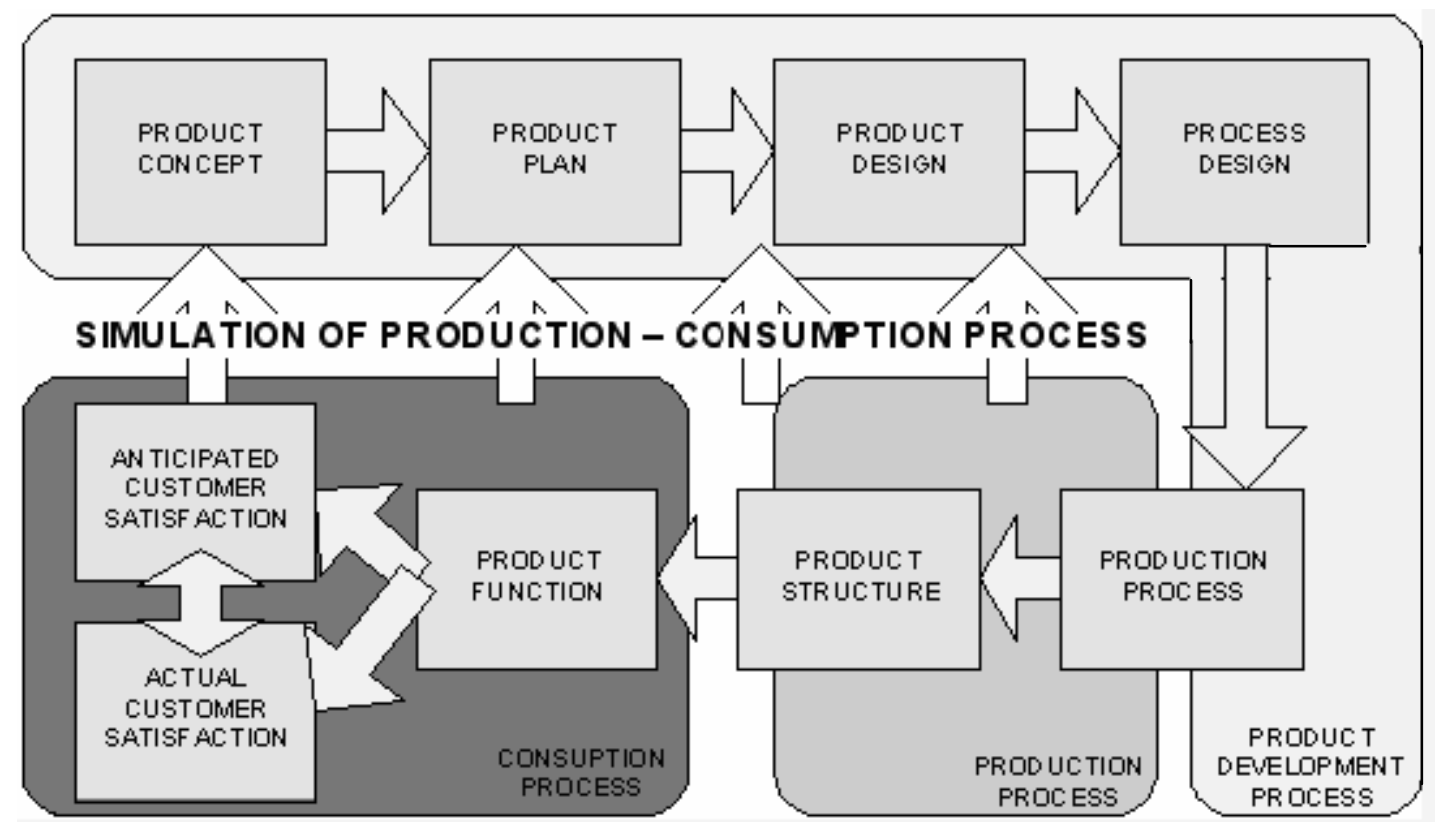

Figure 1: Product development as simulated use [1].

Product development is essentially a simulation of production and consumption. It creates information assets that are intended to represent elements of the future consumption process [1].

This is how sanitary fittings, in their initial phase, represent a prototype of a product, which potential users test and comment on through a set of questionnaires [12]. At the same time, within this process, an analysis takes place at the company to determine the suitability of implementing a project of developing a new product. Test users also play the role of the 
subsequent users of series of products. Test users serve the purpose of simulating the path that the product will have on the market. In this way, it is foreseen how many times fittings will be used daily, monthly, yearly and no damage will be suffered in moving mechanical parts or due to cleaning agents on the surface. Feedback for changes that were malformed during construction is used as simulation. This type of fulfilment of potential needs simulates future developments. The suitability of the choice of the pilot - the initial users of the products tested, is more clearly explained in the literature, for example [2], [4].

Simulation of further development through the design makes it possible to determine the trend and development or guidelines, in the direction of which the new product is developed. The development of simulation is based on the curve, which is assumed to be cyclical in nature and is formed in a multi-dimensional environment.

How well a development group simulates target costumers is a critical to the effectiveness of a product development effort. It is critical to manage the linkages between development and the sources of information about future consumption. This is the reason to analyze customer behaviour and product development concurrently. As customer needs and evaluation criteria change, so do the effective patterns of development [1].

\section{MODEL OF MULTICRITERIA ANALYSIS WITH SIMULATION OF PRODUCT DEVELOPMENT}

The idea of multi-dimensional analysis is presented in greater detail in the article [3]. The independent variable shows the time, dependently forming the most representative parameters of production.

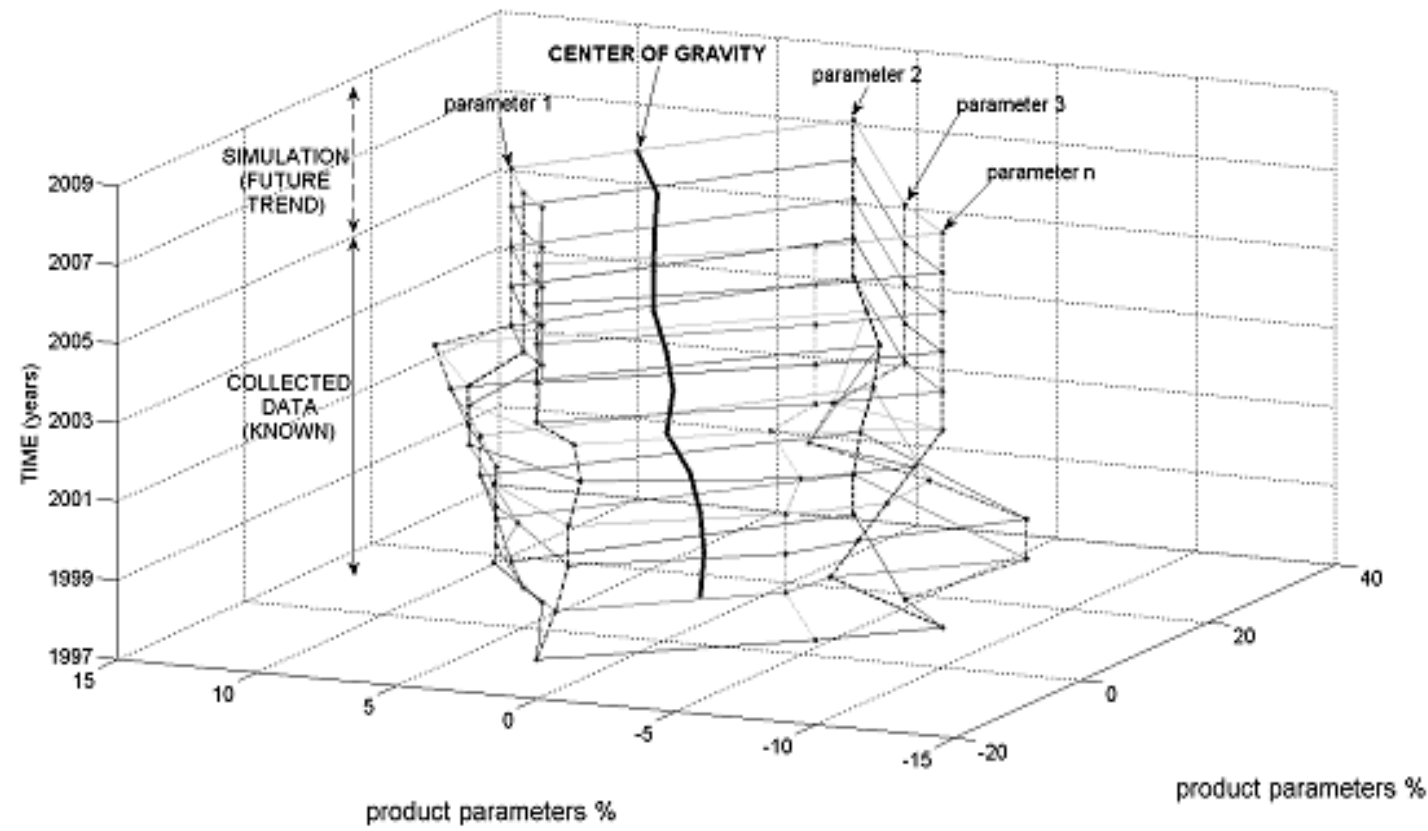

Figure 2: Simulation of product development on the base of collected data in the past.

Fig. 2 displays an outline, which is conceptual and shows the how the development of the new product is simulated in the stage of searching for ideas. Fig. 2 contains collected data, for example, from 1997 to 2005; for each parameter entered, on the basis of this data, development for the future time period is simulated. The focus of the body is the united indicator, which is displayed as a bold line. A more detailed conceptual design of the model has been presented by the authors in the article [3]. This is only a basic explanation of the model. 
The transition from Cartesian coordinates to polar coordinates is given by the following Eq. from (1) to (3). In Eq. (4) we calculate the uniform distribution of the horizontal axes of observed parameters around time - central axis. This uniform way of distribution of product parameters does not emphasise only one parameter but that all parameters are equivalent Eq. (6).

The representative parameters acquired from the company are evenly distributed on the circle arch of $360^{\circ}$ with the centre in coordinate origin. The angle according to Eq. (1) belongs to each parameter; parameter $n$ means the number of representative parameters.

$$
\varphi_{k}=360^{\circ} / n \cdot(n-k) ; \quad k=0,1,2 \ldots . n-1
$$

The percentage value of an individual parameter with belonging angle Eq. (1) is converted to Cartesian coordinates upon Eq. (2) and (3). On the coordinate axis "z" an independent variable time is shown or the period of observation (e.g. from 1997 to 2007).

$$
\begin{aligned}
& x_{k}(\%)=\operatorname{Par}_{k}(\%) \cos \varphi_{k} \\
& y_{k}(\%)=\operatorname{Par}_{k}(\%) \sin \varphi_{k}
\end{aligned}
$$

Each parameter is represented in the form of a point, with three parameters used for representation of the results in three-dimensional space, where parameter $m$ is the number of years observed.

$$
\operatorname{Par}_{k_{\text {kart }}}(\%)=\left(x_{k}, y_{k}, z_{m}\right)
$$

Presentation of results with a polar way of data demonstration is improved since it shows the trend and not just information. The centre of gravity of the surface shape enclosed by polar coordinates of observed parameters is calculated upon Eq. (5) to (9). The shape contains a set of $n$-triangles and the sum of the $n$-centers of the mass of those triangles is the mass centre of one observed time parameter [13].

$$
\begin{aligned}
& S_{i}=\frac{1}{2}\left|\begin{array}{ccc}
x_{k} & y_{k} & 1 \\
x_{k+1} & y_{k+1} & 1 \\
x_{0} & y_{0} & 1
\end{array}\right| ; \quad\left(x_{0}, y_{0}\right)=(0,0) \\
& x_{m}=\frac{\sum_{i=1, k=0}^{n, n-1} S_{i} x_{k}}{\sum_{i=1}^{n} S_{i}} \\
& y_{m}=\frac{\sum_{i=1, k=0}^{n, n-1} S_{i} y_{k}}{\sum_{i=1}^{n} S_{i}}
\end{aligned}
$$

An algorithm draws and calculates polar coordinates for individual periods between the year $m-1$ and the adjacent variable, and the year $m+1$ and the adjacent variable. The year is selected as a time argument typical for the branch since the product and technology changes are relatively slow. 
The representation of the centre of mass in a polar way Eq. (8) to (10) provides complete information related to an individual time period.

$$
\begin{aligned}
& T_{p o l_{m}}=\rho_{m} e^{j \gamma_{m}} \\
& \rho_{m}=\sqrt{x_{m}{ }^{2}+y_{m}{ }^{2}} \\
& \gamma_{m}=\operatorname{tg}^{-1}\left(y_{m} / x_{m}\right)
\end{aligned}
$$

Time as the only independent variable is represented by the central axis in the graph, which is the result of model visualization. The displacement of dependent variables on time shows their importance and development upon time parameter.

There are an arbitrary number of dependent variables in the model. They are configured in the circle around time in the form of uniform distribution. For the purpose of this investigation a model is prepared where data is uniformly distributed.

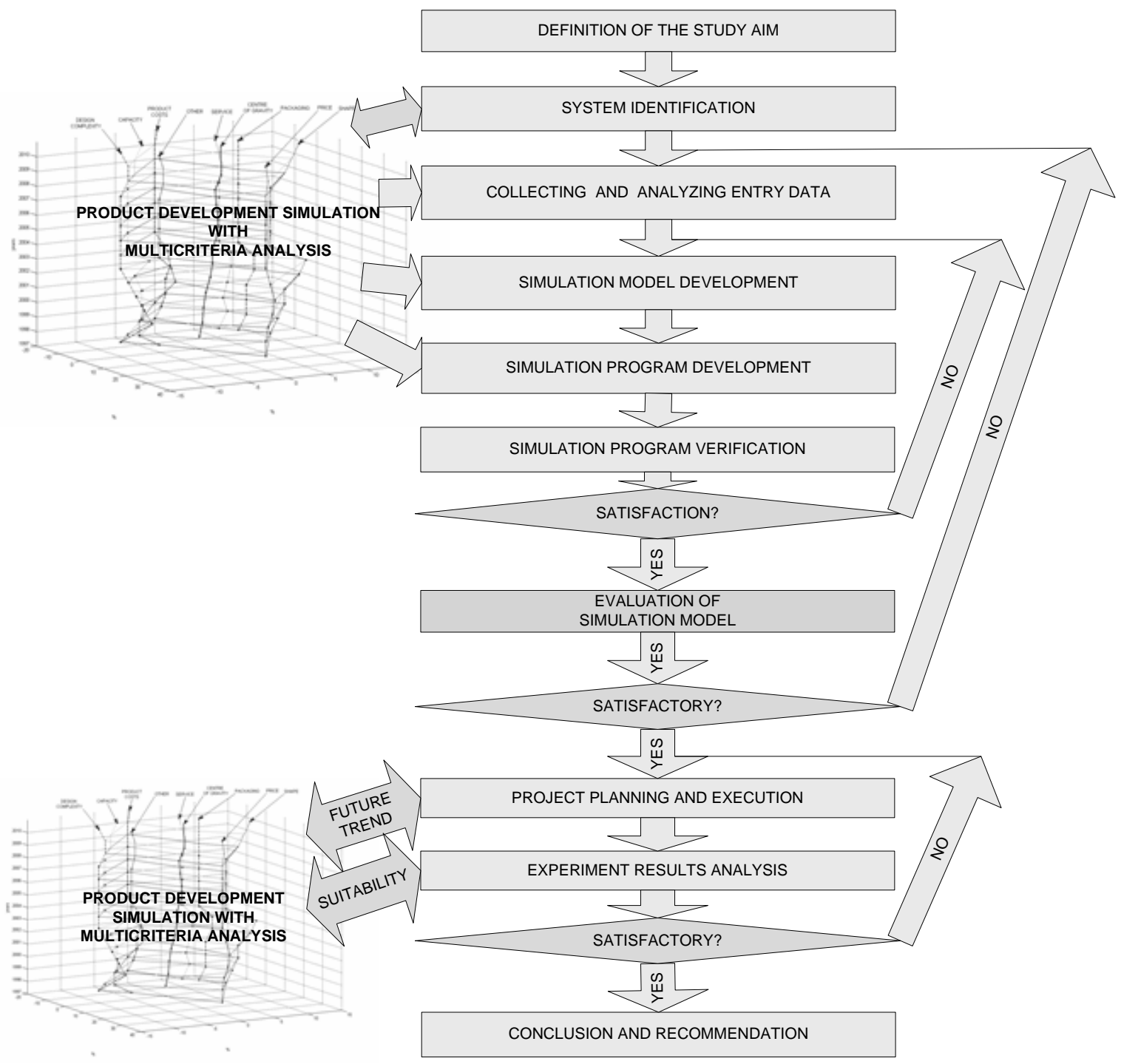

Figure 3: Display of the development of the simulation model with the inclusion of multiparameter analysis. 
Fig. 3 shows a model of multicriteria analysis compared to the simulation process in steps [5]. In both cases, the initial data are the same. The analysis takes place at a time when the data are entered into the set design, which is also a simulation program. Planning and implementation of the project takes place in a similar multi-parameter analysis; it can simulate various parameters of the individual weights, which means that changes in individual parameters simulate the development in each direction. The effectiveness of the correct choice depends on the quality of data, which is entered in the model. During the data analysis, it is determined if the results presented in the multi-parameter analysis are interesting and correct.

With the assistance of multi-dimensional analysis, the model of product development is associated with the simulation model in two areas, namely, before and after the evaluation of the simulation model, where the correct and logical form of the development of a new product is selected and evaluated (e.g. whether it is a large-scale or small-scale product). Collecting and analysing data in the multi-parameter method model is a longer process, as it demands a greater amount of collected data, which should be internal (collected by the company) and external (collected by the market). Both should be balanced in relation to the scope of simulation. The companies with the greatest amount of collected data will be at an advantage. The construction of the simulation model and program is displayed in concept in Fig. 2 and through equation's from Eq. (1) to (10). The verification of the correctness of the model applies, assuming that there is a large-scale product of the same type at regular intervals and that the parameters set on the same axes around a central axis of time. The trend is simulated on the basis of linear dependency.

On the other hand, multicriteria analysis includes simulation evaluation in the planning and implementation of the project in the form of forecasting trends on the basis of the data collected. The trend will show the importance of each variable and its strength in a particular period of time. In analyzing the results of the experimental model, however, a gap of expensive and lengthy tests is filled, along with the search for the most successful new product. The conceptual design of the data path, data capture and data integration in the system is discussed more extensively in the article [3].

\section{CASE STUDY}

There is no in-depth treatment of the development of large-scale products in sanitary fittings. [3]. The field of product development simulation of sanitary fittings, from the standpoint of the production-engineering approach is interesting because it is a complex product.

The sample on which the first model of multi-dimensional analysis is prepared with the intention of product development covers eight time-dependent variables of sanitary fittings. The products observed were sanitary fittings of middle-price range in Slovenia. The price and quality range was assumed on the basis of expert opinions from the branch of sanitary fittings production and from the branch of sanitary fittings suppliers. The number of the chosen sanitary fittings representatives comprises $95 \%$ of the observed range, which is the sixteen most representative products of the middle-priced range of recognised European trade marks that were, and still are, present in the Slovenian market. The price range of up to $110 \mathrm{EUR}$, for which certain marketing and production rules are applicable, is a so-called premium range. The characteristics that were observed in the chosen sanitary fittings were the following: price, shape, packaging, service, production costs, capacity, design complexity, and unclear influences given under the column Other [12].

The established algorithm was modelled in the Matlab programme version 7.6.0.324. This programme enables easy and transparent recording of algorithms. By means of Matlab computing language, which contains a number of other functions for three-dimensional presentations of objects, three-dimensional programming was also performed. 
Kostanjevec, Polajnar, Kostanjevec: Product Development Simulation with Multicriteria ...

Table I: Information gathered from the market and company [1].

\begin{tabular}{|c|c|c|c|c|c|c|c|c|c||}
\hline \multirow{2}{*}{$\begin{array}{c}\text { Time } \\
\text { (years) }\end{array}$} & \multicolumn{9}{|c|}{ Observed parameters } \\
\cline { 2 - 11 } & Price & Shape & $\begin{array}{c}\text { Packa- } \\
\text { ging }\end{array}$ & Service & $\begin{array}{c}\text { Production } \\
\text { costs }\end{array}$ & Capacity & $\begin{array}{c}\text { Design } \\
\text { complexity }\end{array}$ & Other & Total \\
\hline 1997 & 30 & 10 & 5 & 5 & 20 & 10 & 10 & 10 & 100 \\
\hline 1998 & 30 & 11 & 6 & 7 & 17 & 8 & 6 & 15 & 100 \\
\hline 1999 & 31 & 12 & 6 & 6 & 15 & 8 & 7 & 15 & 100 \\
\hline 2000 & 33 & 12 & 6 & 7 & 15 & 8 & 8 & 11 & 100 \\
\hline 2001 & 34 & 14 & 7 & 8 & 13 & 9 & 9 & 6 & 100 \\
\hline 2002 & 32 & 15 & 6 & 7 & 14 & 7 & 8 & 11 & 100 \\
\hline 2003 & 34 & 16 & 4 & 6 & 12 & 8 & 9 & 11 & 100 \\
\hline 2004 & 36 & 18 & 4 & 4 & 11 & 7 & 10 & 10 & 100 \\
\hline 2005 & 37 & 19 & 3 & 3 & 11 & 7 & 7 & 13 & 100 \\
\hline 2006 & 38 & 19 & 2 & 3 & 10 & 8 & 6 & 14 & 100 \\
\hline 2007 & 43 & 17 & 2 & 2 & 12 & 8 & 8 & 8 & 100 \\
\hline \hline
\end{tabular}

"Product excellence" is much broader than basic functionality or technical performance. Customer who have accumulated experience with a product and become sensitive to subtle differences in many product dimensions demand total balance of numerous product characteristics, including basic functions, aesthetics, semantics, reliability, and economy [14]. The extent to which the totality of a product achieves this balance and attracts customers is a measure of product integrity. [11]

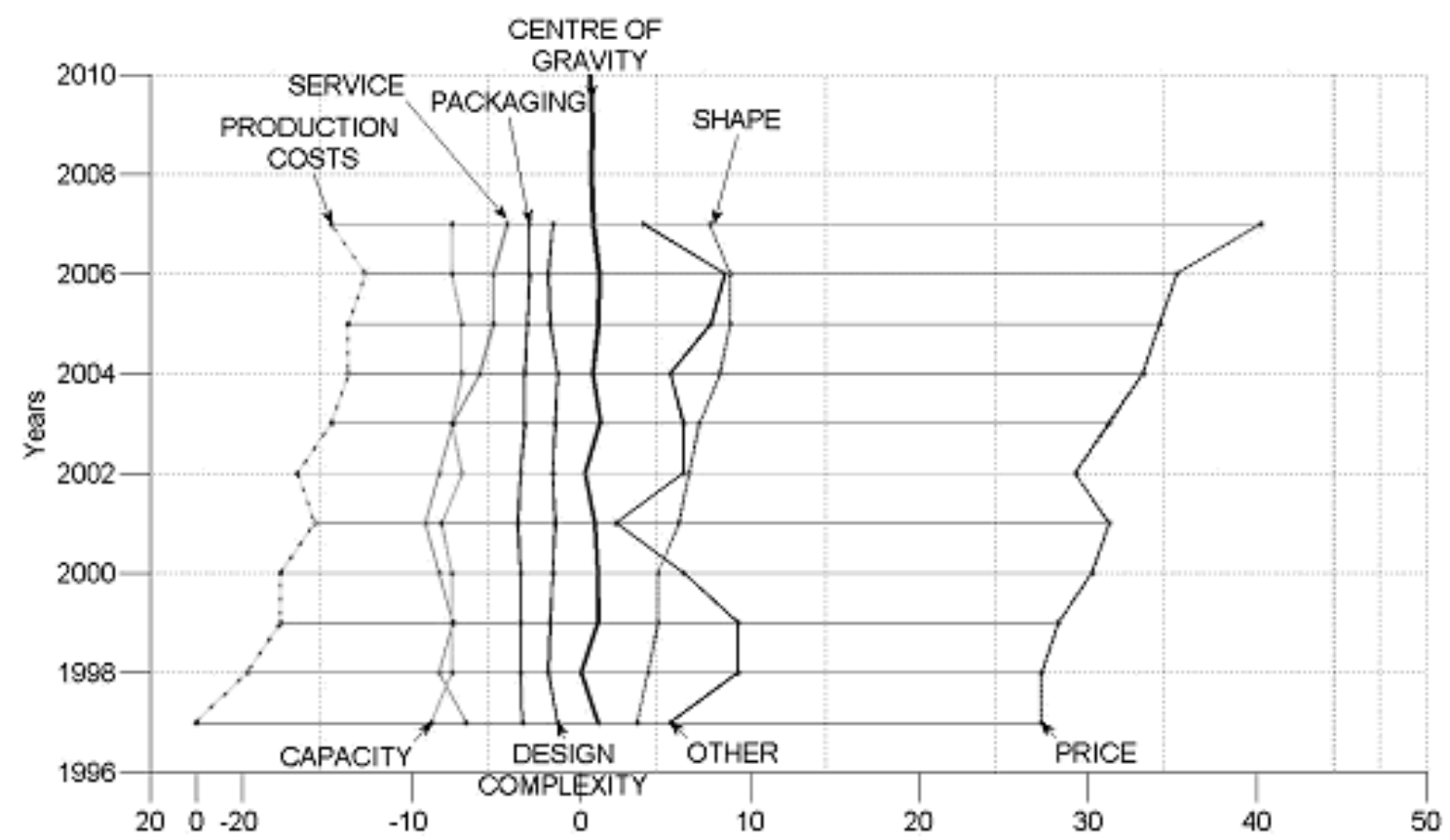

Figure 4: Multi-dimensional motion of product parameter focus of a large-scale product in 2D.

In Fig. 4, a multi-dimensional graph is displayed, in which each parameter in Table I has its own dimension, which is polarly defined. The movement of data for each parameter is independent of other parameters, but they all describe a single product. For this reason, the 
common centre of focus is a generic indicator of the movement of production parameters for the evaluated product. In Fig. 4, all the equations from (1) to (10) are connected. Within the multi-dimensional display, the important lines are the ones in bold. In the polar view in Fig. 6, is the movement of focus in a particular direction and certain intensity. The argument presented in the analysis, that design is of crucial importance, is completely valid. The response to whether or not the balanced method is appropriate for the product, according to the trend, which indicates the direction of design complexity, is affirmative. In this way, the company has the opportunity to address the design complexity and make progress in this field.

Through the simulation of various parameters, in the future, with a model a company can sufficiently indicate the direction in which a product will be developed. Depending on their abilities, especially in terms of production, it can assess whether its development and investing in it make sense and to which extent this is profitable. Considering the direction of product development, it makes sense to create a prototype and test it on the market, which would stand out from the average products and imitate sanitary fittings of a higher price range. The impact of the tests can answer in detail, whether or not the decision is appropriate. It is interesting that the overall analysis of the parameters in [3] showed that the market trend is also directed towards product design. The key parameter is therefore the design model, which emphasizes the use of "different" forms, which should be further explored and determined on the market. A proposal to finding a solution might be a change in the housing design or a change in the approached to sanitary fittings.

With the help of CAD/CAM, the simulation method has obtained a new dimension in the development of new products. In the formation of ideas, it can serve as a key path. The trend, which gives the answer in this case, is linear, but roughly approximated. The movement of the centre of focus is spiral and addressing the trend of this spiral would give a more detailed response to individual parameters within the time of analysis.

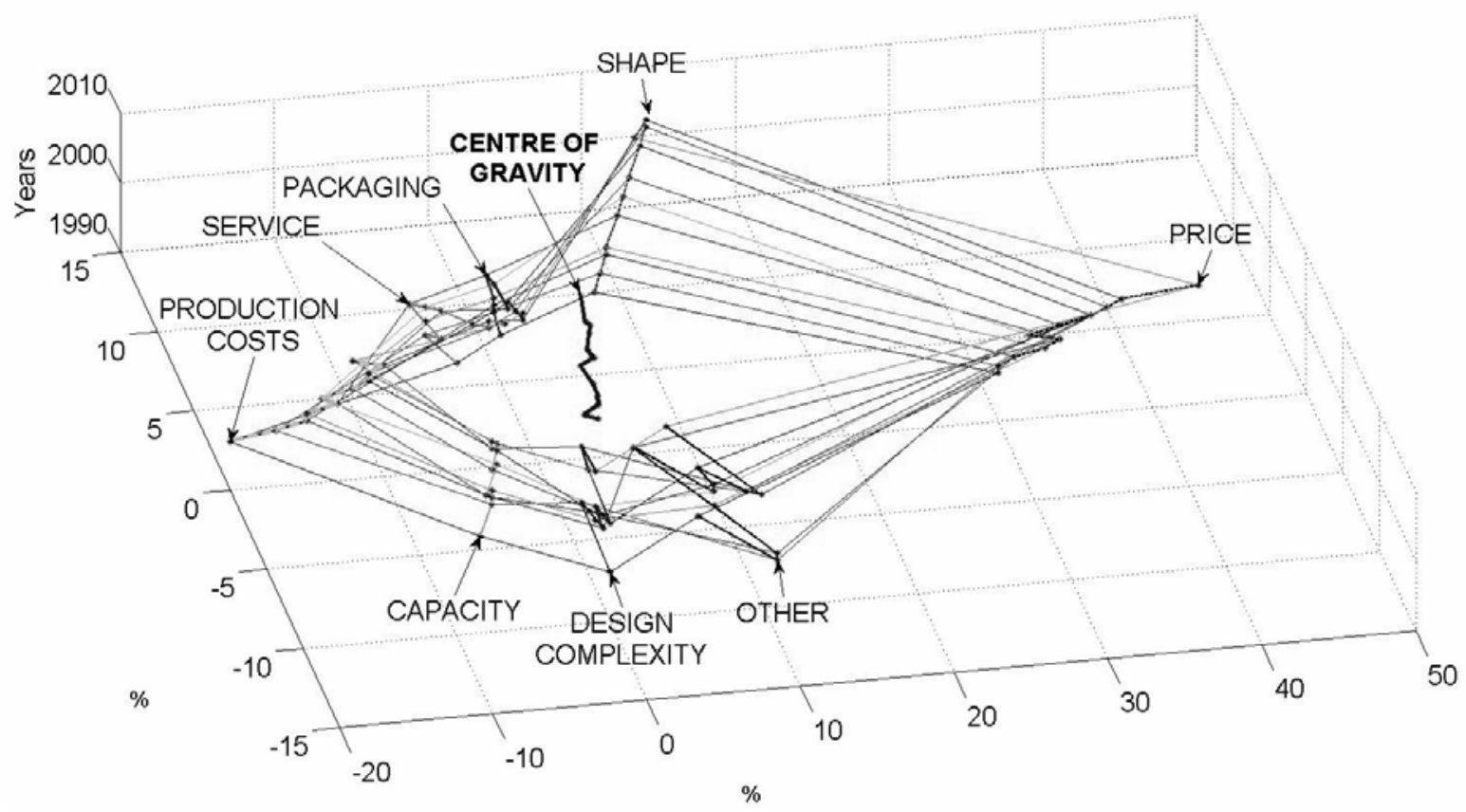

Figure 5: Multi-dimensional motion of product parameter focus of a large-scale product in 3D.

The body displayed in Fig. 5, is a three-dimensional display of the outline shown in Fig. 4. In Fig. 5 it is clear that, despite significant divergence in prices as observed parameters, the 
focus remains in the centre. In Fig. 6, the two-dimensional motion of focus from Fig. 5 can be observed without parameters. Showing all the parameters on paper is difficult because of the plasticity, which would be given to an observer at the simulation of product development. The deviation of prices, as the most important parameter in the referenced case, is balanced with the other parameters, although the absolute value but less with a larger number can balance the importance of price. Movement of focus for 2009 and 2010 is displayed in Fig. 4 to 6.

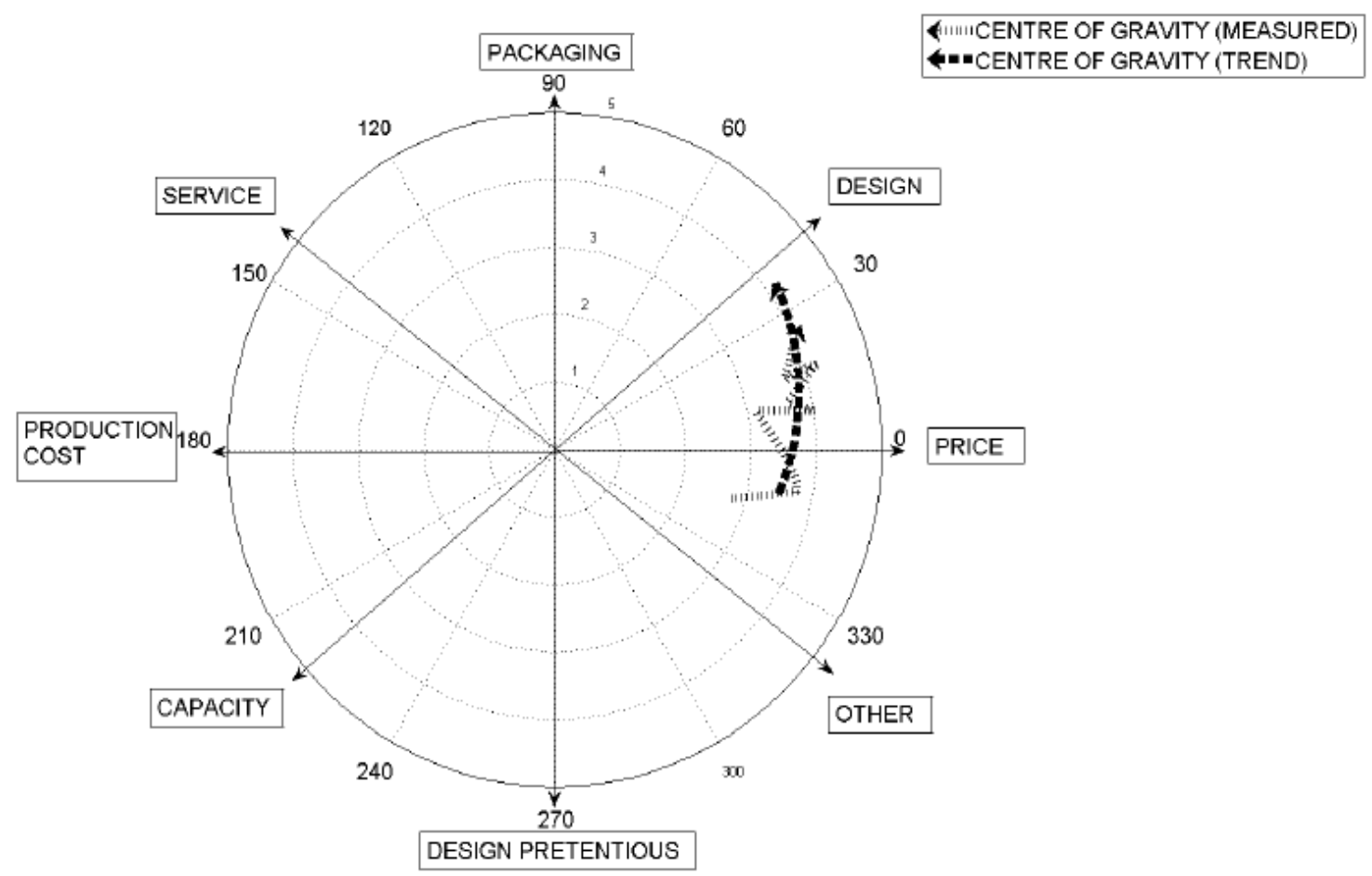

Figure 6: The polar centre of focus based on the several-year observation of parameters [3].

In Fig. 6, the simulation development sanitary fittings between 1997 and 2007 appear in the polar graph with dots; the trend by 2010 is displayed with a line and a dot. Individual axis in Fig. 5 represents the parameters that have been observed in the most important product and are also shown in Fig. 4 and Fig. 5. Based on the multi-dimensional curve, the trend is selected linearly. The option of using a higher level of trend adaptation is possible.

Through the simulation of development, an emphasised role of designs with greater intensity can be anticipated. It is interesting to observe the focus as an aggregate indicator of the movement of the observed parameters. In the early years of 1997 and 1998, the focus was on price, and despite the fact that the importance of price at that segment grew, the importance of forms of 'outweighed' the importance of price. The price is still important, but it is crucial for a company to follow the demands of the market and their internal skills in product design and the strategic orientations of the company.

\section{RESULTS AND CONCLUSION}

In establishing the model, it was found that it is possible through the analysis of the parameters, which were formed by the previous route of the products in the market and in the company, to effectively simulate the path the product will have in the future. The simulated path is mathematically identifiable and verifiable.

The development of the product itself is very unpredictable and still mystical. Until now, simulation of the product development has not given the correct answer. Products that have been developed as prototypes have been delivered to the market, and the success of these 
prototypes has been monitored by companies. The time and price of this time was too high and companies partially disregarded or even phase out this form. There are no tools for the quick and easy creation of ideas. Certainly, the ideas that are interesting in market terms will be better than those, which are not at least in their initial phase of deployment to the market. The presented model displays in what way, on the basis of the information collected to develop a new product idea, a trend of the parameters as a function of time can be made.

The method allows the determination of the importance of a particular parameter in the future and based on simulations, indicates the direction, which product feature will be important, and which the company is exposed to greater success on the market.

Life cycles of technologies, products and processes are becoming shorter, so it is very important to predict the technology for their planning. An alternative form of development of the product incorporates a simple position, in which is a single product in a given time consists of various parameters, complete the whole [3].

The above concept can be developed and completed in all dimensions of modern forecasting product development of mid-range sanitary fittings, which according to mathematical evidence and in accordance with time change, move from the direction of unexplored elements to the direction of product design [3].

Simulation of development with multicriteria analysis is new, which is why it must be tested on other large-scale products. However, we maintain that it is the right path and that with it; it is possible to indicate the direction in which a new product will develop in the early stages of idea development and which will be interesting priorities on the market. Precedence over individual priorities is clearly a balance between the 'internal' and 'external' observed and collected parameters.

\section{REFERENCES}

[1] Clark, K. B.; Fujimoto, T. (1991). Product development performance: strategy, organization, and management in the world auto industry, Harvard Business School Press, Boston (Mass.)

[2] Cooper, R. G. (2001). Winning at new products: accelerating the process from idea to launch, Perseus, Reading (Mass.)

[3] Kostanjevec, T.; Polajnar, A.; Sarjas, A. (2008). Product development through multi-criteria analysis, Journal of Mechanical Engineering, Vol. 54, No. 11, 739-750

[4] Crawford, C. M.; Di Benedetto, C. A. (2008). New products management, McGraw-Hill/Irwin, Boston

[5] Andrew, M. H. (2005). Time savings in product development through continuous simulation, University of Pittsburgh (doctoral thesis)

[6] Kmetovicz, R. E. (1992). New product development: design and analysis, Wiley, New York

[7] The PDMA Handbook of new product development. (2005). Wiley, Hoboken (N. Y.)

[8] Jürgens, U. (2000). New product development and production networks: global industrial experience, Springer, Berlin

[9] Cancer, V. (2007). Okvirni postopek za večkriterijsko odločanje, Organizacija, Vol. 40, No. 5, A160-A167

[10] Glavac, M.; Ren, Z. (2007). Multicriterial optimization of a car structure using a finite element method, Journal of Mechanical engineering, Vol. 53, No. 10, 657-666

[11] Buchmeister, B. (2008). Investigation of the Bullwhip effect using spreadsheet simulation, International journal of simulation modelling, Vol. 7, No. 1, 29-41

[12] Raziskava tržišča (Market research) za potrebe PE Armal: interno gradivo. (2006). Mariborska livarna, Maribor

[13] Bronstejn, I. N.; Semendjajev, K. A. (1978). Matematični priročnik za inženirje in slušatelje tehniških visokih šol, Tehniška založba Slovenije, Ljubljana

[14] Novak, M.; Dolsak, B. (2008). Intelligent FEA-based design improvement, Engineering Applications of Artificial Intelligence, Vol. 21, No. 8, 1239-1254 